\title{
EDITORIAL
}

\section{A SOCIEDADE CIVIL ORGANIZADA NO CONTEXTO DA MOBILIDADE HUMANA}

\section{Organised Civil Society in the context of human mobility}

A atuação da Sociedade Civil (SC) junto a pessoas migrantes e refugiadas, frequentemente discreta senão invisível, tornou-se nos últimos anos, e em vários países, cada vez mais manifesta e midiática por um processo de estigmatização e criminalização por parte de segmentos da sociedade abertamente hostis a políticas de acolhimento, proteção e integração de pessoas em mobilidade. Se no passado a ação solidária era tida como louvável, ainda que, em determinados contextos, ingênua e instrumentalizável, hoje, sobretudo nos países onde imperam abordagens nacionalistas e sovranistas, se tornou uma ação antipatriótica e até criminosa.

O que chama a atenção neste cenário é a paradoxal utilização do léxico dos direitos humanos para demonizar práticas solidárias que visam promover a dignidade dos sujeitos envolvidos. Em outros casos, ao contrário, o paradigma dos direitos é aplicado de forma seletiva, unicamente a um determinado grupo de pessoas, os nacionais, ou parte deles. Neste caso, entende-se que a sociedade é e deve ser dividida em "castas" (Carens, 1987), com diferentes graus de direitos. O crime de muitas organizações da SC, nesta perspectiva, seria a negação dessa hierarquização. Consequentemente, com a SC é criminalizada a egalité de todos os seres humanos.

Para além desse processo de estigmatização e de criminalização, a ação da SC - movimentos, associações, organizações de cunho religioso e laicos, ou outros grupos mais ou menos formais - não deixa de enfrentar sérios desafios. Em primeiro lugar, cabe ressaltar que a atuação da SC não é homogênea, nem necessariamente a favor dos direitos de pessoas migrantes e refugiadas. Os grupos de minutemen nos EUA são uma clara evidência. É mister evitar,

Editor-chefe da Revista REMHU, Centro Scalabriniano de Estudos Migratórios (CSEM). Brasília DF, Brasil. E-mail: remhu@csem.org.br. Orcid: 0000-0002-2042-2628. 
portanto, essencializar a SC como sendo inevitavelmente comprometidas com princípios democráticos (Nogueira, 2003) e com a promoção dos direitos humanos das pessoas em mobilidade.

No que diz respeito às organizações da SC especificamente engajadas em prol dos direitos de migrantes e refugiados, há um conjunto de desafios que surgem na interlocução e na interação com os poderes públicos dos quais a Sociedade Civil tende a reivindicar autonomia (Cohen 2004): como evitar o risco que a ação da SC acabe por substituir a ação do Estado e, por vezes, legitimar sua omissão? Além disso, até que ponto os financiamentos públicos, que várias organizações da SC recebem, podem interferir nas políticas e nos critérios de atuação, levando em conta que, na atualidade, a maioria das políticas estatais privilegia e sustenta abordagens securitárias? Em outras palavras, como amenizar os riscos da SC renunciar à imprescindível função de contestação em relação ao imperialismo estatal e economicista (Cohen, 2004, p. 428), em busca de alternativas sistêmicas?

Um último conjunto de desafios diz respeito à tipologia de intervenção da SC junto às pessoas em mobilidade. Há uma diversificação de abordagens, que vão do atendimento emergencial, passando pela promoção humana integral, até ao engajamento em lutas sistêmicas e estruturais. Vários estudos apontam para uma constante adaptação das abordagens das organizações da SC em decorrência das alterações das dinâmicas migratórias e, inclusive, das políticas públicas. Seja como for, um sério desafio é constituído pela crescente substituição do léxico - e da lógica - dos direitos para o léxico da compaixão e da solidariedade, com o consequente deslocamento do foco do "direito" da pessoa migrante para o "dever" da pessoa acolhedora (Fassin, 2018, p. 278). Além disso, cabe avaliar a posição atribuída às pessoas migrantes e refugiadas no amplo processo de acolhimento: as narrativas vitimizantes, funcionais para despertar a solidariedade, podem reificar a condição das pessoas atendidas e menosprezar ou até eliminar sua agency (Fassin, 2018, p. 280). O risco é que a ação da SC acabe, de fato, promovendo dinâmicas de "domesticação", de "docilização", que respondam essencialmente às lógicas securitárias.

Finalmente, em meio a tanto desafios, cabe destacar também o surgimento de "redes transnacionais", ou de uma "sociedade civil transnacional", caracterizada pela conexão e pelo entrelaçamento de organizações locais por intermédio do ciberespaço, o que permite a universalização de experiências e lutas locais (Cohen, 2004, p. 435). Os objetivos dessas redes são vários, mas focam, sobretudo, em políticas de produção simbólica, incidência política e responsabilização. Cabe avaliar como essas redes transnacionais podem contribuir para fortalecer as lutas migrantes e das organizações da SC que os apoiam. 
Sobre essas temáticas verte o Dossiê da REMHU, Revista interdisciplinar da Mobilidade Humana, n. 58.

No primeiro artigo, María Isolda Parrelló Carrascosa e Joan Lacomba abordam o trabalho de organizações da SC pro-migrantes em duas fronteiras extremamente desafiadoras: a do México-EUA e da Espanha-Marrocos. Os autores analisam e comparam os dois casos, destacando como as prioridades de atuação das organizações da SC, laicas e religiosas, estão atreladas aos contextos específicos, envolvendo questões econômicas - principalmente as formas de dependência de dinheiro público ou de organismos internacionais - e questões políticas - locais, nacionais e regionais - onde paradigmas humanitários interagem e, com frequência, se chocam com aqueles securitários. Neste contexto, o desafio principal, na ótica dos autores, é articular o engajamento assistencialista, a luta pelos direitos humanos e, inclusive, o compromisso pela denúncia e pela mudança das políticas migratórias, mesmo quando isso implica formas de retaliação - "las organizaciones han sido acusadas desde medio oficiales de promover la inmigración irregular o, incluso, de colaborar con las mafias que trasladan a las personas migrantes".

As temáticas da estigmatização e da criminalização são aprofundadas por Aline Fabiana Campos Pereira, com foco no caso da Hungria. Após apresentar um sólido quadro teórico sobre o conceito de "desviantes sociais" a autora sustenta a problematicidade de aplicar essa categoria oriunda da sociologia do desvio para o caso de pessoas que violam leis com vistas a defender direitos fundamentais de seres humanos em mobilidade ou outras causas análogas. Diante disso, Campos Pereira sugere a utilização dos conceitos de "supranormalidade" - em oposição à "a-normalidade" - e "desvio positivo" para designar pessoas que agem fora da norma, mas numa perspectiva da promoção dos direitos humanos. A autora pondera que, diferentemente de outros casos, na Hungria a estigmatização precedeu ou se deu de forma paralela à criminalização dos ativistas, o que significa que uma campanha de difamação pode pavimentar os caminhos para a criminalização legal.

A criminalização da ação solidaria da sociedade civil é focada também por Eduardo Torre Cantalapiedra a partir do estudo do caso do México. O autor apresenta a conjuntura e os eventos que marcam a prisão de lideranças pro-migrantes no contexto do surgimento e da evolução das assim chamadas "caravanas". Conforme Torre Cantalapiedra, no México ocorre uma coyotización "prática" e "narrativa" dos defensores dos direitos humanos que são presos (coyotización prática) com a acusação de tráfico de pessoas e estigmatizados pelos meios de comunicação social e órgãos oficiais dos governos (coyotización narrativa) como sendo atrelados a essa prática criminosa. Segundo o autor, no México, esse processo de estigmatização e de 
criminalização dos defensores dos direitos humanos é uma consequência das políticas de externalização das fronteiras do país vizinho.

Ainda sobre esse tema, Luca Giliberti foca sua reflexão na fronteira entre Itália e França. Apesar dos acordos de Shengen, o surgimento de fronteiras internas na União Europeia tem despertado a solidariedade de numerosos atores da sociedade civil, que atuam de maneira informal e/ou institucionalizada, visando oferecer ajuda emergencial, denunciando as violações e - inclusive buscando auxiliar o projeto migratório das pessoas atendidas. O artigo, entre outros aspectos, ressalta a divisão no interior da sociedade civil, caracterizada por grupos solidários - sobretudo entre os assim chamados neorurais, pessoas que se deslocaram voluntariamente para a região em busca de um novo estilo de vida - e grupos hostis, principalmente entre os que residem no lugar há gerações. Os dois grupos visam "defender o território", mas com perspectivas totalmente diferentes. De fato, a questão migratória se tornou na região, assim como em outros contextos, um verdadeiro "campo de batalha" (Ambrosini, 2020) onde se enfrentam diferentes modelos de sociedade.

Irene Carrano, Daniela Chiringhelli e Claudia Tagliabue apresentam uma experiência concreta de acolhimento familiar (Rifugiati in famiglia) numa ação coordenada entre órgãos governamentais, sociedade civil, núcleos familiares acolhedores e refugiados na cidade de Milão. Trata-se de uma experiência de integração doméstica que não quer e nem pode substituir as políticas de acolhimento governamentais, mas que possibilita uma complementação e um enriquecimento cidadão no amplo e complexo processo de "integração". De forma específica, as autoras destacam como os diferentes atores envolvidos são chamados a abandonar sua zona de conforto, abrir mão de parte do seu "poder", a fim de desencadear um "circuito virtuoso" que permita um enriquecimento recíproco e, principalmente, o reconhecimento do protagonismo e da autonomia das pessoas refugiadas, num processo de integração bidirecional.

Peter Müller, por sua vez, a partir de uma pesquisa realizada na fronteira norte do México, analisa a atuação de organizações da SC em ambos os lados da fronteira. O autor apresenta a evolução da estruturação e da atuação dessas organizações, que se destacaram pela perseverança, flexibilidade e capacidade de construir redes formais ou informais, atuando desde as formas mais elementares de assistência até o monitoramento das violações e da incidência política. Na parte final, Müller analisa os resultados da pesquisa a partir do trabalho de Didier Fassin, principalmente no que diz respeito aos limites da ação "de cima para baixo" de governos e organizações internacionais e locais. Conforme o autor, no caso estudado, a ação da SC tende a seguir, com frequência, um rumo diferente, "de baixo para cima", tendo uma forte vinculação com a comunidade local e as pessoas migrantes. 
María Gabriela Rho se debruça sobre a evolução dos movimentos sociais de e em favor de migrantes no contexto argentino, levando em conta fatores como o contexto político e legislativo, o histórico de luta de movimentos sociais e, sobretudo, as recentes transformações provocadas pela inclusão e pelo impacto das organizações de trabalhadores desempregados e excluídos, bem como de novas formas de organização protagonizadas por jovens migrantes e filhos de migrantes. $\mathrm{O}$ artigo ressalta como a confluência desses vários fatores levou a mudanças expressivas em termos de estratégias de organização, espaços de luta e articulação, com destaque pela assunção das lutas de classe, a priorização da articulação com outros movimentos sociais, a opção pelas mobilizações nas ruas e do protagonismo das pessoas migrantes na articulação das pautas de luta.

No último artigo do Dossiê, Flávia Rodrigues de Castro se debruça sobre a complexa questão da determinação do status de refugiado no Brasil, realizada pelo CONARE com o envolvimento de um membro da Sociedade Civil. O artigo utiliza a categoria de "injustiça epistêmica" no contexto da assim chamada "economia da credibilidade", para descrever um processo em que as pessoas solicitantes de refúgio estão envolvidas mais como investigadas que como sujeitos de conhecimento. Desta forma, as várias etapas do processo de elegibilidade estão condicionadas por estereótipos e preconceitos, excessos e déficits de credibilidade atribuídos aos vários atores, bem como a reações emocionais que podem produzir formas de injustiça epistêmica. Neste contexto, a atuação de um membro da sociedade civil não deixa de ser ambivalente, na medida em que busca limitar as condições que geram injustiças, mas, por outro lado, se torna parte e, de alguma forma, legitimadora do processo.

$* * *$

Na seção Artigos, André Zuzarte aborda o tema das assim chamadas cidades-santuário. Sem romantizar a temática, o autor reconhece, com Lefebvre, que as cidades podem fortalecer políticas restritivas e securitárias, mas, também, promover processos alternativos de inclusão, na perspectiva da apropriação do território e da participação cidadã para todos os moradores citadins, em francês - e não apenas para aqueles a quem o Estado reconhece a cidadania política - citoyens.

Juan Carlos Ortíz Ruíz, Sheyla Dafne Aguilar Magaña e María Elena Rivera Heredia analisam o processo do translado de corpos de migrantes mexicanos do Estados de Michoacán falecidos nos EUA. O artigo aprofunda o assunto de forma quantitativa, a partir de dados estatísticos, e qualitativa, mediante entrevistas a familiares das vítimas. O doloroso processo é interpretado como um "retorno" da pessoa migrante para sua terra e suas mães, o que contribui, 
em parte, na elaboração do processo de luto, amenizando sofrimentos e incertezas.

Giuliana De Battista aprofunda a questão das migrações climáticas no contexto africano. Sem cair no determinismo, a autora busca evidenciar a interdependência entre diferentes fatores - econômicos, políticos, históricos, étnicos e climáticos - na causalidade dos fluxos migratórios. Diante disso, ressalta a necessidade de ampliar a noção jurídica de "refugiado" para além da restritiva definição da Convenção de 1951 e dos protocolos adicionais.

Sobre o tema dos "refugiados ambientais" se debruça também Carolina de Abreu Batista Claro. Tendo como base os principais instrumentos internacionais de proteção da pessoa humana, a autora destaca a necessidade de amparar as pessoas envolvidas em novas tipologias de migração forçada, que envolvem também a questão ambiental, explorando a normativa já existente ou mediante a formulação de novos tratados internacionais específicos.

Na seção Relatos e reflexões, Silvia Maria Hirsch e Areli Veloz apresentam uma breve crônica de uma pesquisa realizada em 2019 na fronteira norte do México. As pesquisadoras relatam os principais resultados de entrevistas e encontros com migrantes e Organizações da Sociedade Civil, focalizando sobretudo a questão de gênero.

Carmem Lussi, por sua vez, se debruça sobre a experiência espiritual e eclesial de pessoas migrantes brasileiras que vivem na Itália. Fruto de uma pesquisa realizada em 2017, o relato destaca as contribuições que a Igreja católica brasileira pode oferecer para a Igreja italiana, sobretudo no que diz respeito à liturgia, à relação fé-vida e ao laicato.

A resenha de Roberto Marinucci sobre o livro L'invasione immaginaria. L'immigrazione oltre i luoghi comuni de Maurizio Ambrosini encerra o número da revista.

Desejamos a todas e todos uma boa leitura.

\section{Referências bibliográficas}

AMBROSINI, Maurizio. L'invasione immaginaria. L'immigrazione oltre o luoghi comuni. Bari: Laterza, 2020.

CARENS, Joseph. Aliens and Citizens: The Case for Open Borders. The Review of Politics, v. 49, n. 2, p. 251-273, 1987.

COHEN, Jean. Sociedade Civil de Globalização: repensando categorias. DADOS Revista de Ciências Sociais, Rio de Janeiro, v. 46, n. 3, p. 419-459, 2003.

FASSIN, Didier. Ragione umanitaria. Una storia morale del presente. Roma: DeriveApprodi, 2018.

NOGUEIRA, Marco Aurélio. Sociedade Civil, entre o Político-Estatal e o Universo Gerencial. RBCS, v. 18, n. 52, p. 185-202, junho 2003. 